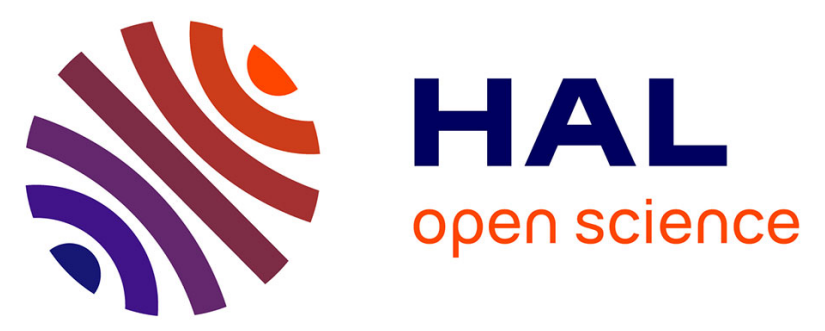

\title{
Impact of Lockdowns and Winter Temperatures on Natural Gas Consumption in Europe
}

\author{
Philippe Ciais, Francois-Marie Breon, Stijn Dellaert, Yilong Wang,
} Katsumasa Tanaka, Léna Gurriaran, Yann Françoise, Steven J Davis, Chaopeng Hong, Josep Penuelas, et al.

\section{To cite this version:}

Philippe Ciais, Francois-Marie Breon, Stijn Dellaert, Yilong Wang, Katsumasa Tanaka, et al.. Impact of Lockdowns and Winter Temperatures on Natural Gas Consumption in Europe. Earth's Future, 2022, 10 (1), 10.1029/2021ef002250 . hal-03580314

\section{HAL Id: hal-03580314 https://hal.science/hal-03580314}

Submitted on 18 Feb 2022

HAL is a multi-disciplinary open access archive for the deposit and dissemination of scientific research documents, whether they are published or not. The documents may come from teaching and research institutions in France or abroad, or from public or private research centers.
L'archive ouverte pluridisciplinaire HAL, est destinée au dépôt et à la diffusion de documents scientifiques de niveau recherche, publiés ou non, émanant des établissements d'enseignement et de recherche français ou étrangers, des laboratoires publics ou privés.

\section{(ㅇ)(1) $\$$}

Distributed under a Creative Commons Attribution - NonCommercial - NoDerivatives| 4.0 


\title{
Earth's Future
}

\section{RESEARCH ARTICLE 10.1029/2021EF002250}

\author{
Special Section: \\ The COVID-19 pandemic: \\ linking health, society, and \\ environment
}

\section{Impact of Lockdowns and Winter Temperatures on Natural Gas Consumption in Europe}

\author{
Philippe Ciais $^{1}$ (D), François-Marie Bréon ${ }^{1}$, Stijn Dellaert ${ }^{2}$ (D), Yilong Wang ${ }^{1,3}$ (D), \\ Katsumasa Tanaka $^{1,4}$ (D), Léna Gurriaran', Yann Françoise ${ }^{5}$ (D), Steven J. Davis ${ }^{6}$ (D), \\ Chaopeng Hong $^{7}$, Josep Penuelas ${ }^{8,9}$ (D), Ivan Janssens ${ }^{10}$ (D), Michael Obersteiner ${ }^{11}$, Zhu Deng' ${ }^{12}$, and \\ Zhu Liu ${ }^{12}$
}

${ }^{1}$ Laboratoire des Sciences du Climat et de l'Environnement, IPSL CEA CNRS UVSQ, Gif sur Yvette Cedex, France, ${ }^{2}$ Department of Climate, Air and Sustainability, TNO, Utrecht, The Netherlands, ${ }^{3}$ Key Laboratory of Land Surface Pattern and Simulation, Institute of Geographical Sciences and Natural Resources Research, Chinese Academy of Sciences, Beijing, China, ${ }^{4}$ Earth System Risk Analysis Section, Earth System Division, National Institute for Environmental Studies (NIES), Tsukuba, Japan, ${ }^{5}$ Division Climat-énergies économie Circulaire, Agence d'écologie Urbaine, Paris, France, ${ }^{6}$ Department of Earth System Science, University of California, Irvine, CA, USA, ${ }^{7}$ Institute of Environment and Ecology, Tsinghua Shenzhen International Graduate School, Tsinghua University, Shenzhen, China, ${ }^{8} \mathrm{CREAF}$, Cerdanyola del Vallès, Catalonia, Spain, ${ }^{9} \mathrm{CSIC}$, Global Ecology Unit CREAF-CSIC-UAB, Bellaterra, Catalonia, Spain, ${ }^{10}$ Department of Biology, Research Group Plants and Ecosystems (PLECO), University of Antwerp, Wilrijk, Belgium, ${ }^{11}$ International Institute for Applied Systems Analysis (IIASA), Ecosystems Services and Management, Laxenburg, Austria, ${ }^{12}$ Department of Earth System Science, Tsinghua University, Beijing, China

Supporting Information may be found in the online version of this article.

Correspondence to:

P. Ciais and Y. Wang,

philippe.ciais@cea.fr;

wangyil@igsnrr.ac.cn

Citation:

Ciais, P., Bréon, F.-M., Dellaert, S., Wang, Y., Tanaka, K., Gurriaran, L., et al. (2022). Impact of lockdowns and winter temperatures on natural gas consumption in Europe. Earth's Future, 10, e2021EF002250. https://doi org/10.1029/2021EF002250

Received 11 JUN 2021

Accepted 20 DEC 2021

Author Contributions:

Conceptualization: Philippe Ciais Data curation: Philippe Ciais, Stijn Dellaert, Yilong Wang, Yann Françoise, Josep Penuelas, Ivan Janssens, Michael Obersteiner

Formal analysis: Philippe Ciais, François-Marie Bréon Investigation: Philippe Ciais Methodology: Philippe Ciais

(C) 2021 The Authors. Earth's Future published by Wiley Periodicals LLC on behalf of American Geophysical Union. This is an open access article under the terms of the Creative Commons Attribution-NonCommercial-NoDerivs License, which permits use and distribution in any medium, provided the original work is properly cited, the use is non-commercial and no modifications or adaptations are made.

\begin{abstract}
As the COVID-19 virus spread over the world, governments restricted mobility to slow transmission. Public health measures had different intensities across European countries but all had significant impact on people's daily lives and economic activities, causing a drop of $\mathrm{CO}_{2}$ emissions of about $10 \%$ for the whole year 2020. Here, we analyze changes in natural gas use in the industry and gas distribution to the built environment during the first half of year 2020 with daily gas flows data from pipeline and storage facilities in Europe. We find that reductions of industrial gas use reflect decreases in industrial production across most countries. Surprisingly, natural gas use in the built environment also decreased despite most people being confined at home and cold spells in March 2020. Those reductions that we attribute to the impacts of COVID-19 remain of comparable magnitude to previous variations induced by cold or warm climate anomalies in the cold season. We conclude that climate variations played a larger role than COVID-19 induced stay-home orders in natural gas consumption across Europe.
\end{abstract}

Plain Language Summary Despite most of the population confined in spring 2020 across Europe, the consumption of natural gas and pertaining $\mathrm{CO}_{2}$ emissions by the residential and commercial sector was stable or slightly reduced, once air temperature effects are removed.

\section{Introduction}

Natural gas use accounts for $\approx 38 \%$ of the fossil fuel $\mathrm{CO}_{2}$ emissions in Europe, including the EU27 and UK (Eurostat, 2021). The share of this fossil fuel in the energy mix has been growing since 1990 at the expense of oil and coal, as it is viewed as a cleaner source of energy (IEA, 2021). The main sectors using natural gas are the built environment (residential, public and commercial buildings), the industry, and the electricity production (Eurostat, 2021). In addition to steadily growing natural gas use, the COVID-19 pandemic profoundly disrupted economic activities and the energy demand, beginning in early March of 2020. Specifically, the government policies restricted mobility and confined people at home during "lockdowns", and reduced or closed industrial and non-essential commercial activities, with impacts on gas use and pertaining $\mathrm{CO}_{2}$ emissions. Although such impacts have been noted by recent reports (IEA, 2020a, 2020b), they have not yet been quantified and analyzed in detail.

During the cold season period when the pandemic arrived in Europe, natural gas consumption is typically high due to the heating demand in the built environment, which represents $52 \%$ of the total gas consumption from all-sectors averaged over January to June. For both residential and commercial buildings, gas consumption is typically inversely proportional to daily air temperature when temperatures fall below a comfort threshold "critical 
Software: François-Marie Bréon, Yilong Wang

Writing - original draft: Philippe Ciais, François-Marie Bréon, Katsumasa Tanaka Writing - review \& editing: Philippe Ciais, Katsumasa Tanaka, Léna Gurriaran, Steven J. Davis, Chaopeng Hong temperature". Therefore, the lockdowns occurred during a decreasing trend of the heating demand, as temperatures increased from winter to spring. One interesting research question is to quantify and understand the sign and magnitude of natural gas consumption changes, given the opposing effects of people's confinement in households (likely more gas use), the closure of commercial and public buildings (likely less gas use) and the temporary shut-down of industry (likely less gas use). Given different national characteristics and different reductions of industrial activities between European countries during lockdowns, a second interesting question is how industrial gas use was affected in 2020. Natural gas use variations in the electricity production sector have been addressed by Bertram et al. (2021) and Liu et al. (2021) and will not be discussed here.

Changes in natural gas consumption during the COVID-19 pandemic translate into roughly proportional changes of $\mathrm{CO}_{2}$ emissions from the combustion of that fuel. Overall, across all fuels and sectors, the reduction in socio-economic activities due the pandemic caused a strong decrease of $\mathrm{CO}_{2}$ emissions in Europe, and the globe. Two recent estimates of the reduction of $\mathrm{CO}_{2}$ emissions during 2020 have been produced, using activity data, by Le Quéré et al. (2020) and Liu et al. (2020). In both studies, $\mathrm{CO}_{2}$ emissions from the built environment were the most poorly constrained of all sectors because no direct activity data was available to estimate them. Lacking natural gas consumption data for the built environment, Le Quére et al. (2020) made the simple assumption that emissions from the built environment were reduced in every country by generalizing observed residential use of electricity in the United Kingdom under different levels of confinements. Although the underlying data includes the effect of climate factors for the period when they were collected, their correspondence table between activity reduction and confinement indexes, and the use of time series of confinement indexes to infer time series of emissions reductions implicitly assumes that all the change of emissions was caused by confinements. In other words, the focus of their study was to estimate the fraction of emissions reductions attributable to COVID-19, not to separate emission changes due to COVID-19 versus other factors. The contribution of climate factors was thus ignored, even though climate and weather variations strongly influence the heating demand and emissions from gas. In contrast, Liu et al. (2020) estimated daily residential $\mathrm{CO}_{2}$ emissions changes during 2020 by assuming that only climate variables were influential. They used daily air temperature data from ERA5 (Hersbach et al., 2018) with pre-established temperature functions from Crippa et al. (2020) to calculate daily residential emissions in 2020, disaggregating annual baseline emissions from the EDGAR database (Janssens-Maenhout et al., 2017) to daily residential emissions with population-weighted heating degree days in each country.

Here, we analyzed daily natural gas use changes from January to June 2020 in Belgium, France, Germany, Italy, the Netherlands, Poland, Spain and the UK (Methods). We collected and harmonized data separated into the electricity production sector, the industry and 'distribution', which comprises the gas consumption of the built environment. In addition, we collected specific natural gas use data for the city of Paris (Methods). We attempt to analyze whether there has been an increase of gas consumption in the built environment due to a larger number of people being confined at home or a decrease due to closure of commercial buildings, and to separate the effect of temperature variations from those of socioeconomic activity changes.

\section{Natural Gas Consumption Variations Influenced by Temperature}

As an example, we analyzed daily gas use within the city of Paris, which reflects only the built environment (residential, public and commercial buildings). Paris is an easy case with the same temperature exposure and rather homogeneous housing types, dominated by collective buildings equipped with centralized gas heaters. Figure 1 illustrates the relative impact of temperature anomalies and lockdown measures. Figure 1a (left) shows the consumption as a function of the reference climatological temperature of each day during the period from 1 March to 1 June, when confinement occurred in 2020. The reference temperature increases during the period chosen, and can be seen here as a proxy of the date. 1 March is on the left while the May data points are on the right. At the very beginning of the period (left-most data points), the 2020 consumption appears larger than that of 2019. Yet, later on, in particular during the confinement period, the 2020 consumption appears lower than that of 2019, which could be interpreted as an impact of COVID-19 reducing the gas consumption. However, Figure $1 \mathrm{~b}$ (right) shows a different perspective: when the same data is shown as a function of the actual (rather than climatological) temperature, there is no apparent difference between 2019 and 2020 and the scatter of the data-points is reduced. These two figures illustrate clearly the important role of the temperature to drive short term variations of gas use, and the need to account for temperature anomalies when looking for the impact of another predictor like the COVID-19 lockdowns severities. For the city of Paris, we conclude that the impact of 

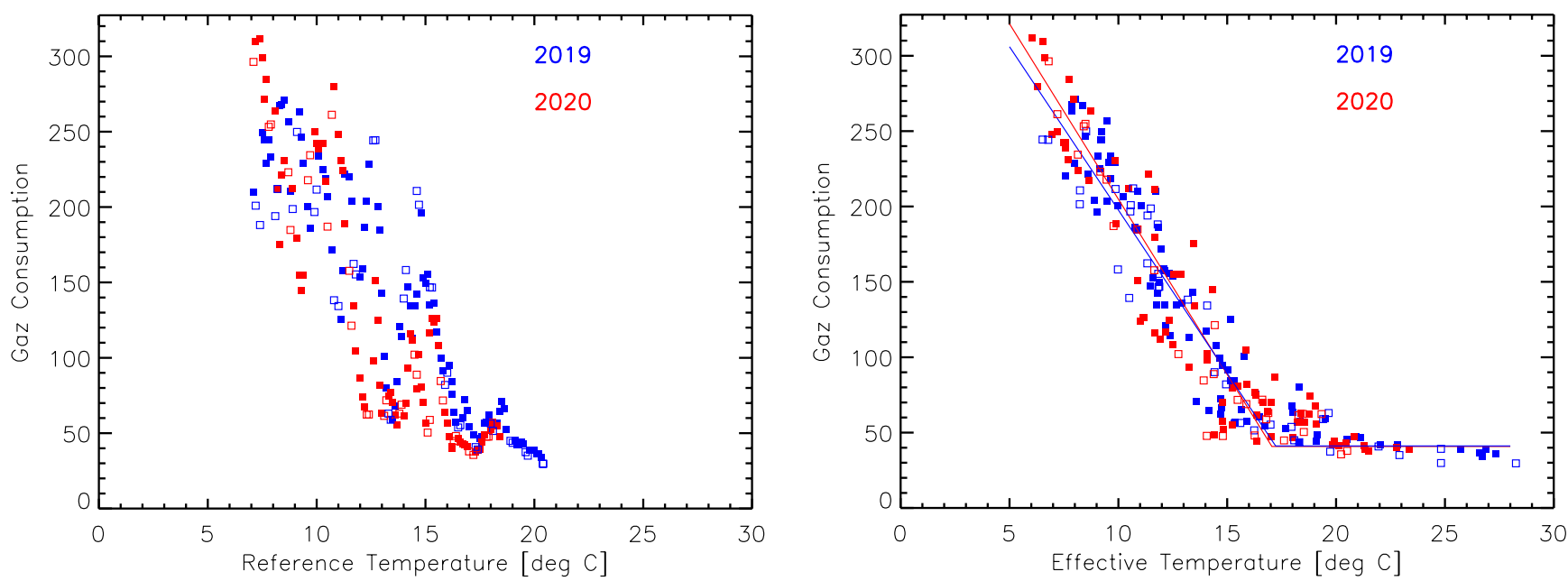

Figure 1. Daily gas consumption within the Paris city from 1 March to mid-June of 2019 and 2020. The gas consumption is shown as a function of the climatological temperature (a proxy of the date; left) and as a function of the effective (actual) temperature each year (right), a representation that removes the effect of daily temperature fluctuations (see text). Filled symbols are for the weekdays whereas the open symbols are for week-ends and holidays.

temperature anomalies on the gas consumption in the built environment is much larger than that of the COVID-19 lockdown on natural gas consumption, despite most of the population being confined at home under a very strict confinement. Any quantitative analysis of interannual variations due to the lockdown or other measures must be based on temperature-corrected data.

We then analyzed daily gas supply data at national scale (Methods) for eight European countries that provided separate estimates for different sectors. Compared to the Paris case, one additional difficulty is the definition of a temperature that is representative for each country. For this, we used the ERA-5 re-analysis (Hersbach et al., 2018) and calculated a population-weighted average of air temperature over each country's area, accounting for a temporal-lag impact of temperature: the consumption is not only dependent on the temperature of the day, but also to that of the previous days (a building has some thermal inertia, especially if it contains concrete, bricks or stone, which is common in Europe). Namely, we computed an effective temperature based on the temperature at days D-2, D-1, and D-0, with respective weights $0.55,0.30$, and 0.15 . This effective temperature was defined to obtain the best correlation with gas consumption.

In all the countries, daily gas use shows a decreasing trend with increasing temperature, up to a temperature $T_{\text {crit }}$ above which there is no apparent sensitivity to temperature. Examples of this behavior are shown on Figure 2 for the industry and the built environment in France. For the built environment, it is interesting to see in Figure 2 that the consumption during week days is larger than during weekends (Table 1). On the basis of these figures, we devised piecewise linear models to fit consumption with temperature. The models were fitted against 2016-2019 daily data points with three parameters: $T_{\text {crit }}$, the base gas consumption for temperature above $T_{\text {crit }}$, and the slope of the linear relationship between temperature and gas consumption for temperatures below $T_{\text {crit }}$. There is little difference on slope of the T-consumption relationship for France, but the base consumption independent of the temperature is significantly different between week-days and weekends (the difference is 6 times larger than the uncertainty on the base value, $p<0.04$ ). This is counter-intuitive as one could expect a larger residential consumption during the weekend when people spend more time at home. A likely explanation is that the gas distribution data include commercial and public buildings that are closed during Saturdays and Sundays. The weekday-weekend difference is rather small for Germany, but goes up to $\approx 50 \%$ for France (Table 1 ). The industry sector shows a number of "low" outliers for France in Figure 2, most of which are for 2020 and they all occur during the lockdown period, according to Oxford Covid-19 Government Response Tracker data (OxCGRT) (Hale et al., 2020). Similar negative outliers are observed for the industry in Italy and Spain, but Poland, Germany and UK show positive outliers in the first half of 2020 (Figure S1 in Suppporting Information S1). 

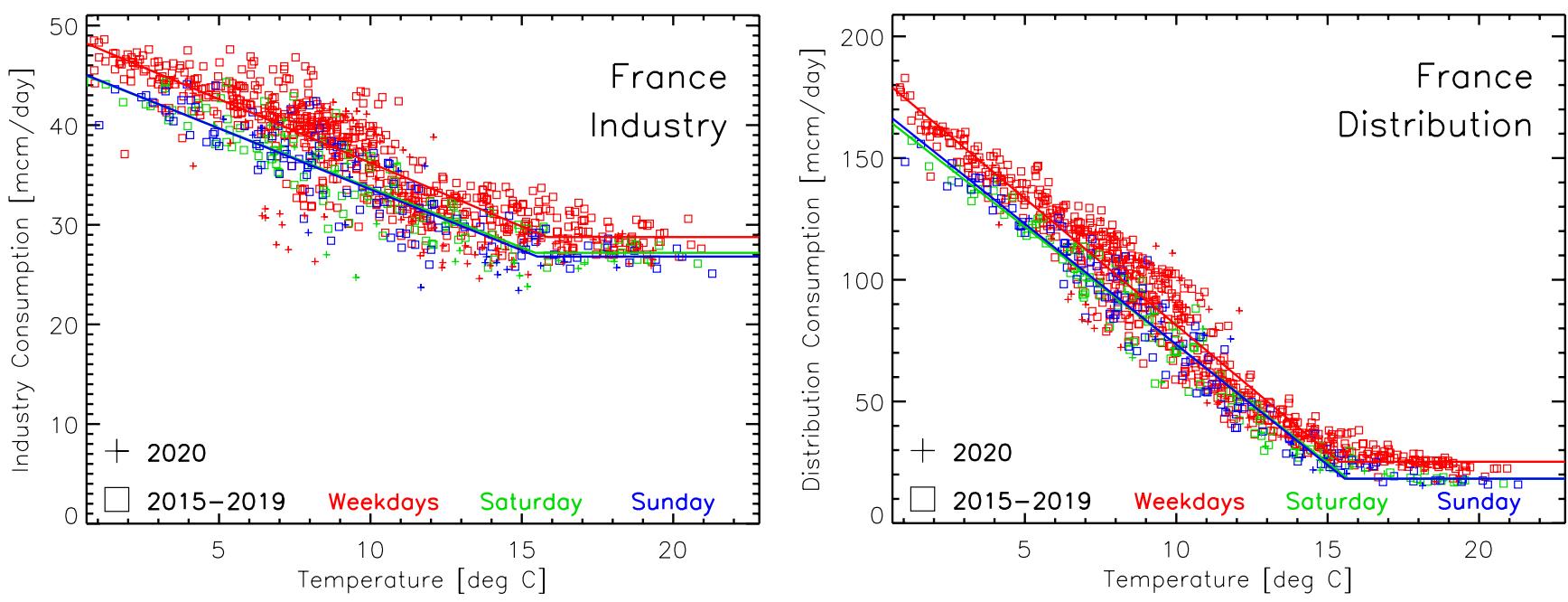

Figure 2. Daily gas consumption in France as a function of the effective temperature (see text) by the industry (left) and gas distribution to the built environment (right).

\section{Countries Differences in the Temperature Sensitivity of Natural Gas Consumption}

There is a high correlation $\left(R^{2}>0.9\right)$ between the actual consumption and the one which is predicted by our piecewise linear models, indicating that air temperature is a very good predictor of short-term gas consumption anomalies during the cold season, despite the large range of mean winter temperature between southern and northern countries. Across the eight countries analyzed, the critical temperature $T_{\text {crit }}$ obtained from the piecewise linear models is remarkably stable between weekdays, Saturdays and Sundays (a few tenths of a degree differences) and varies from $\approx 14^{\circ}$ in the $\mathrm{UK}$ to $\approx 16^{\circ}$ in Italy with a broad North-South gradient (Table 1 ). This could possibly reflect an acclimation to colder temperatures for people leaving in the North, or just better insulated buildings in the North. Conversely, the correlations for the industry sector are much smaller, indicating that temperature is not the only predictor of industrial gas consumption variability, and that there are country differences (Figure S1 in Supporting Information S1). In Poland, the Netherlands and the UK, the slope of the industrial gas consumption versus temperature tends to be smaller than in other countries (Figure S1 in Supporting Information S1).

We found that the per capita mean slope (2016-2019) of gas consumption versus temperature which defines the temperature sensitivity of gas use in the built environment, differed between countries, reflecting different degrees of building insulation, habits of people, and possibly prices of natural gas. The base (independent of temperature) per capita consumption more likely other uses of gas, such as cooking or water heating. The base per capita varies between 0.37 and $0.93 \mathrm{~m}^{3} \mathrm{cap}^{-1} \mathrm{day}^{-1}$, although Poland is an exception with much smaller values (Table 1). The temperature-dependant sensitivity varies between 0.16 and $0.39 \mathrm{~m}^{3} \mathrm{cap}^{-1} \mathrm{day}^{-1} \mathrm{deg}^{-1}$, again with Poland outside of this range. Poland appears to be an outlier because it has a smaller share of dwellings and population using gas as a heating source; gas represents only $7 \%$ of the heating consumption in terms of final energy use in Poland, against 41\% for coal, 20\% for biomass and 29\% of district heat (Economidou et al., 2011). Gas is not much used in Poland for space heating and non-space heating applications. The temperature sensitivity of natural gas use per capita should be directly related to the energy need for residential heating. Using building average national data from different databases on energy use (Methods) and gas heated floor area, we found a strong positive linear relation with the gas used temperature sensitivity and the per capita average gas heated floor area (Figure 3). The country with the largest per capita gas heated floor area is the Netherlands, and the smallest is Poland. The strong correlation shown in Figure 3 implies that the temperature sensitivity of natural gas use per capita depends primarily on the heated floor area per capita, in other words that country differences in insulation for gas heated buildings are of secondary importance. Using detailed subnational data at city or district level instead of national data as in this study, may reveal that other factors control the temperature sensitivity of gas consumption, like the types of building (collective vs. individual) and their insulation characteristics/energy efficiency which generally decrease with building age. It is also possible that other meteorological variables such 
Table 1

Result of the Temperature Dependent Piecewise Linear Models Applied to Daily Natural Gas Consumption Data, as Illustrated in Figure 2

\begin{tabular}{|c|c|c|c|c|c|c|c|c|}
\hline & \multicolumn{5}{|c|}{ Distribution } & \multicolumn{3}{|c|}{ Industry } \\
\hline & $\begin{array}{c}T_{\text {crit }} \\
{\left[{ }^{\circ} \mathrm{C}\right]} \\
\end{array}$ & $\begin{array}{c}\text { Slope }[\mathrm{mcm} / \\
\left.\text { day } /{ }^{\circ} \mathrm{C}\right]\end{array}$ & $\begin{array}{c}\text { Base }[\mathrm{mcm} / \\
\text { day] }\end{array}$ & Correlation & $\begin{array}{l}T_{\text {crit }} \\
{\left[{ }^{\circ} \mathrm{C}\right]} \\
\end{array}$ & $\begin{array}{c}\text { Slope }[\mathrm{mcm} / \\
\left.\text { day } /{ }^{\circ} \mathrm{C}\right]\end{array}$ & $\begin{array}{c}\text { Base }[\mathrm{mcm} / \\
\text { day] }\end{array}$ & Correlation \\
\hline \multirow[t]{3}{*}{ Italy } & 15.9 & 14.43 & 37.5 & 0.914 & 15.5 & 0.58 & 28.5 & 0.226 \\
\hline & 16.0 & 13.70 & 28.1 & 0.907 & 8.6 & -0.61 & 30.9 & 0.258 \\
\hline & 16.4 & 12.93 & 26.5 & 0.909 & 9.5 & -0.58 & 29.7 & 0.173 \\
\hline \multirow[t]{3}{*}{ Spain } & & & & & 17.7 & 0.58 & 47.5 & 0.727 \\
\hline & & & & & 16.4 & -0.61 & 39.5 & 0.843 \\
\hline & & & & & 17.1 & -0.58 & 39.1 & 0.724 \\
\hline \multirow[t]{3}{*}{ France } & 15.4 & 10.41 & 25.3 & 0.951 & 15.8 & 1.28 & 28.8 & 0.813 \\
\hline & 15.7 & 9.70 & 18.3 & 0.961 & 15.4 & 1.20 & 27.2 & 0.827 \\
\hline & 15.6 & 9.91 & 18.3 & 0.950 & 15.5 & 1.22 & 26.8 & 0.793 \\
\hline \multirow[t]{3}{*}{ Belgium } & 14.6 & 2.50 & 8.0 & 0.938 & 15.1 & 0.70 & 12.6 & 0.824 \\
\hline & 14.4 & 2.40 & 6.4 & 0.945 & 15.0 & 0.63 & 11.6 & 0.802 \\
\hline & 14.7 & 2.36 & 6.4 & 0.935 & 15.3 & 0.66 & 11.6 & 0.778 \\
\hline \multirow[t]{3}{*}{ Netherlands } & 13.5 & 6.66 & 16.1 & 0.924 & 15.2 & 0.85 & 22.1 & 0.289 \\
\hline & 13.4 & 6.48 & 13.3 & 0.925 & 14.6 & 0.49 & 23.4 & 0.242 \\
\hline & 13.6 & 6.30 & 12.9 & 0.920 & 16.0 & 0.54 & 23.3 & 0.335 \\
\hline \multirow[t]{3}{*}{ UK } & 13.6 & 13.56 & 57.3 & 0.904 & 10.6 & 0.78 & 23.5 & 0.602 \\
\hline & 13.8 & 13.23 & 50.3 & 0.883 & 9.3 & 0.69 & 23.8 & 0.485 \\
\hline & 14.0 & 12.83 & 50.7 & 0.859 & 11.5 & 0.73 & 21.8 & 0.520 \\
\hline \multirow[t]{3}{*}{ Germany } & 14.9 & 15.28 & 31.1 & 0.964 & 19.3 & 1.24 & 61.9 & 0.312 \\
\hline & 14.9 & 15.04 & 29.4 & 0.959 & 14.6 & 2.18 & 49.8 & 0.595 \\
\hline & 15.0 & 14.92 & 30.4 & 0.952 & 14.2 & 2.55 & 50.7 & 0.739 \\
\hline \multirow[t]{3}{*}{ Poland } & 15.0 & 1.35 & 15.5 & 0.933 & 146.5 & -0.00 & 18.7 & 0.006 \\
\hline & 15.2 & 1.31 & 13.9 & 0.935 & -6.4 & -0.01 & 18.0 & -0.167 \\
\hline & 15.0 & 1.29 & 14.0 & 0.935 & 39.9 & 0.01 & 17.8 & 0.027 \\
\hline
\end{tabular}

Note. For each cell of the table, the results for weekdays, Saturdays and Sundays are provided. For Spain, the consumption data could not be separated between distribution (built environment) and industry.

as humidity, surface radiation, and sunshine duration play an additional role in determining the amount of natural gas use in the built environment.

\section{Changes Between the Lock-Down and Pre-Lockdown Periods}

We first look at changes in gas consumption in the built environment. The winter 2019-2020 has been exceptionally mild over Europe, with a warming anomaly of $\approx 1^{\circ} \mathrm{C}$ from December to March, compared to the climatology of our study period (Hersbach et al., 2018). At the beginning of lockdowns however, between mid-to-late March and early April, a succession of colder than normal weather events occurred, bringing cold spells over western Europe. When removing the effect of these cold spells using the piecewise linear models described above, we display in Figure 5 the changes of gas consumption in the built environment in France that are not explained by temperature during the pre-lock-down period (15 January to 1 March 1st) and the lockdown period (1 March 1st to 1 June). In Italy, France, Belgium, the Netherlands and Poland, we found a relative reduction larger than one standard deviation of variations between the two periods during other years (Figure 5). On the other hand, in the UK and Germany, there is a small relative increase during the lockdown periods as compared to the pre-lockdown reference period, but this change remains within the one standard deviation of other years. This difference might 


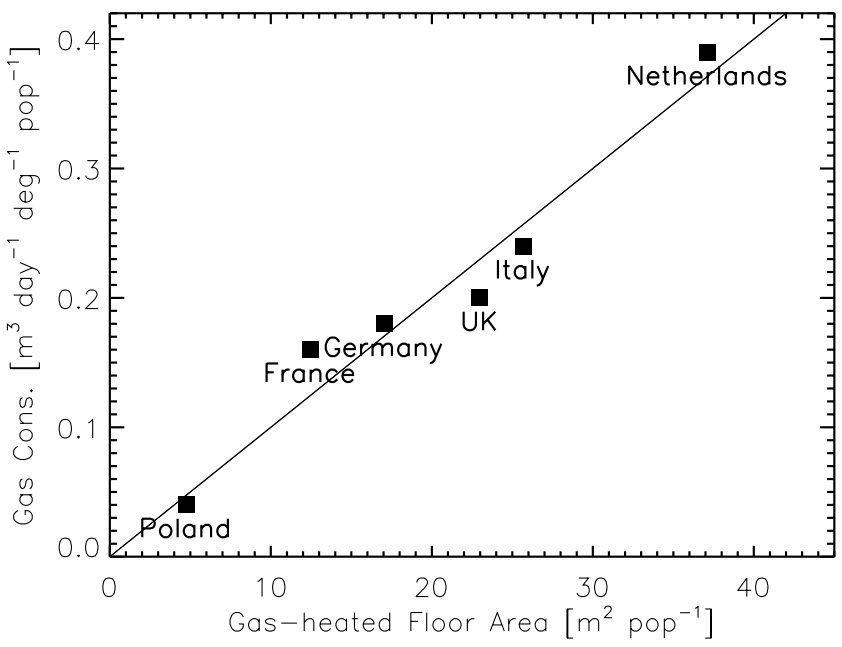

Figure 3. Regression between the temperature sensitivity of natural gas deliveries to the distribution network (the increase in per capita consumption per unit decrease of effective air temperature) and the per capita housing area, for houses heated by natural gas. The strong regression between the six countries suggests that building insulation and energy efficiency differences have small effects in controlling the sensitivity, as compared to the space available per capita. be explained by the large share of residential buildings heated by natural gas in the UK and Germany, and by less stringent lock-down measures that allowed a fraction of people to continue to remain in workplaces. This result indicates that despite nearly all the population being confined at home all day long in Spain, Italy and France, and the strong mobility reduction, for example, by $75 \%$ in France (Pullano et al., 2020), the natural gas consumption rather decreased than increased. This may be due to some residential buildings being empty, compensating for other full households, and to closed commercial and public buildings with reduced or no heating.

In the seven countries where gas consumption data for the built environment was available, we regressed daily anomalies of gas consumption corrected for temperature against the OxCGRT government response indexes, and the Google mobility indexes (relative presence at home) for the period 1 March-1 June 2020. Marginally significant $(p<0.10)$ and weak negative correlations were found for all countries, except in Germany (where positive correlation was found between daily anomalies of gas consumption corrected for temperature and OxCGRT response index with $p=0.03$, and no significant correlation was found between daily anomalies of gas consumption corrected for temperature and Google mobility index) and UK (where positive correlations were found), which had less strict confinements than other countries (Figure S2 in Supporting Information S1). These correlations between government response indexes (lockdowns severity) and gas consumption are impaired by the sparsity of data with lockdowns lasting less than 30 days during the cold season when gas is used for heating, and by the fact that OxCGRT indexes take discrete values and stall to zero when lockdowns are released. Regressions with Google mobility data were also weak, but they show the same negative correlation signs as the OxCGRT data. These generally negative correlations suggest that overall, empty commercial and public buildings accounted for a drop of gas consumption larger than any increase from fully occupied residential buildings. Our data did not separate commercial from residential buildings to prove this hypothesis, but an analysis of gas use data in the US confirmed that most of the reductions in gas consumption came from the commercial sector (Hong et al., 2021).

The industry sector gas consumption is not as temperature-dependent as the built environment is. Nevertheless, a temperature correction was applied from linear piecewise models fitted to daily consumption data from the industry sector, similarly to the data processing of the built environment sector, to properly identify the consumption anomalies that are linked to the lockdown. The time series of industry gas consumption is shown in Figure 4 for France as an example. On this figure, the impact of the lockdown is very clear, with a strong and rapid decrease of the consumption just after the start of the lockdown. The consumption returned to near normal values after about two weeks, once adequate procedures had been put in place in the industries.

Figure 5 summarizes the inter-annual relative variations of the gas consumption during 2020 and previous years, for the industry and the built environment. Consumption relative deviations from normal values (2016-2019 mean) are shown. The figure also shows the variation between "pre-lockdown" and country specific "lockdown" periods defined from Hale et al. (2020). For the industry sector, the largest impact is over Italy, with a $25 \%$ decrease in consumption. Again, the lockdown impact is also very clear for this sector in France, Spain, Italy and Poland. For UK and the Netherlands, there was no decrease of gas use by the industry during the lock down, consistent with the fact that in May 2020, these two countries had the smallest decrease of industrial production among the eight countries considered (Eurostat, 2020). As for the built environment, most countries show a small decrease in gas consumption of $10 \%-20 \%$, but there is no such signal over Germany and the UK, where mobility was less restricted than in the other countries studied. 

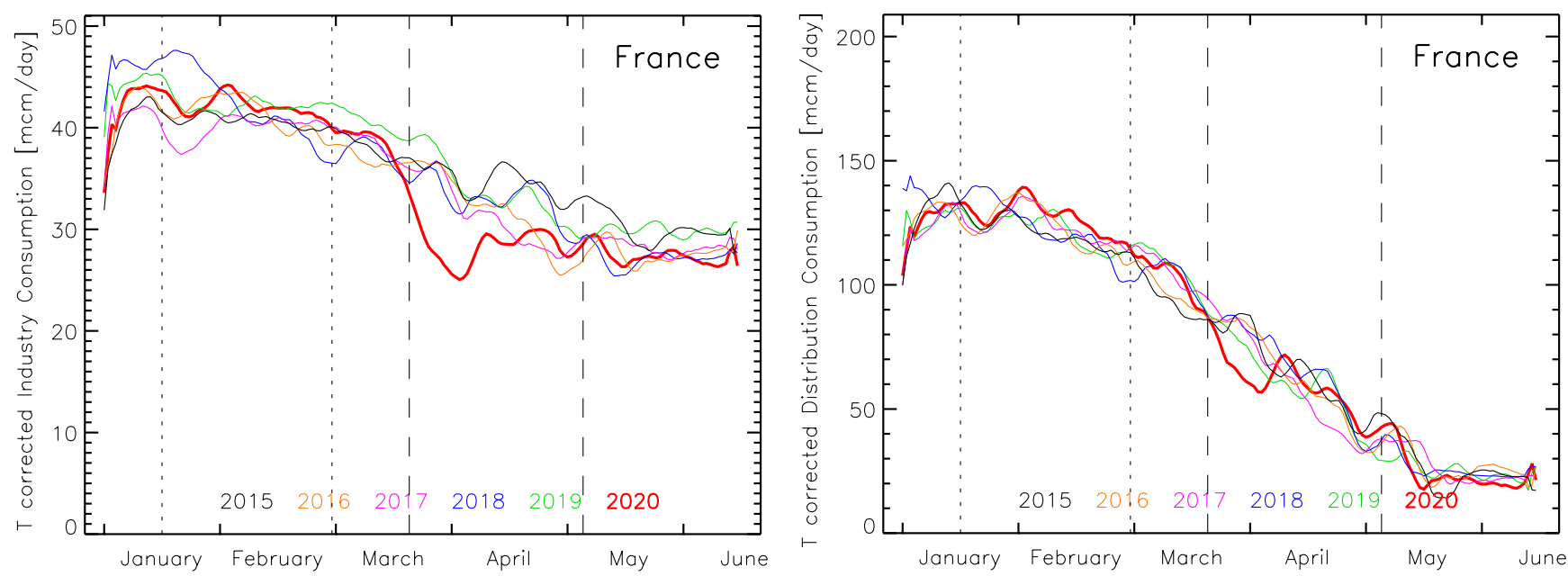

Figure 4. Time series of the daily natural gas consumption by the industry (left) and distribution to the built environment (right). Gas consumption values have been corrected for temperature anomalies using piecewise linear models (that are different for weekdays, Saturdays and Sundays), as in Figure 2, and time series are made smoother using the boxcar method over a period of 7 days. Vertical dotted lines define the pre-lock-down period and dashed lines the lock-down periods, used in Figure 5.

\section{Conclusions}

Our results show that the largest impact of COVID-19 response measures natural gas use was on the reduction of natural gas consumption by the industry sector in Italy (25\%), France (16\%), and Spain (14\%), but also considerable and shorter duration reductions in Germany and Poland. Meanwhile, the lockdowns also caused a net decrease of gas distribution to the built environment, by roughly $15 \%$ in each of Italy, Belgium, the Netherlands, and Poland. However, the anomalies in gas use in the built environment due to COVID-19 lockdowns (after removing the effect of temperature), are of the same magnitude as the anomalies related to temperature differences in normal years. Contrary to the results of Le Quéré et al., (2020) who calculated $\mathrm{CO}_{2}$ emissions in the residential sector based on residential electricity consumption, the gas consumption data suggest that $\mathrm{CO}_{2}$ emissions from gas use in the built environment did not decrease in proportion to the intensity of COVID-19 confinements in each country (Figure 5). We do not have data for residential emissions from other fuels like oil and coal, the latter being important for heating in Poland. Nonetheless, our data suggest that temperature is indeed the dominant factor influencing gas-related emissions in the cold season. However, in six of the eight countries studied, we detected an additional (not temperature-related) reduction in $\mathrm{CO}_{2}$ emissions that we tentatively attribute to COVID-19. Better interpretation of changes in 2020 will require more detailed spatial information about natural gas use patterns, associated with specific building types down to city or district levels, which is achievable through analyses of gas distribution network flows and smart-meters data.

\section{Methods}

First, we collected data on daily natural gas flows toward distribution and final consumption in each country reported by operators to the ENTSO-G transparency platform (Entso-G Transparency Platform, 2020). For the eight countries considered, daily gas deliveries in $\mathrm{kWh}$ /day were downloaded from the ENTSO-G platform for the period of 1 January 2016 to the latest available data. For most countries, the gas data was separated between distribution and final consumers, the latter one typically representing industry and power plants. For Belgium, final consumption was further divided in industrial use and power plants. For Germany, the data available on the ENTSO-G platform appeared to be incomplete. For this reason, daily gas consumption data was downloaded from online portals of GASPOOL (https://www.gaspool.de/en/) and NetConnect Germany (https://www.net-connect-germany.de/en-gb/), the two main consortia of transmission system operators in Germany, and used instead of the ENTSO-G data. Since $\mathrm{CO}_{2}$ emissions are highly correlated with the energy content of the gas, no further conversion was necessary. Distribution in the ENSTO-G data corresponds to the consumption of gas in the built environment as a whole, and dominates the total gas consumption in each country. The data did not separate commercial, public and residential buildings. For this sector, gas is mainly used for space heating and secondarily 

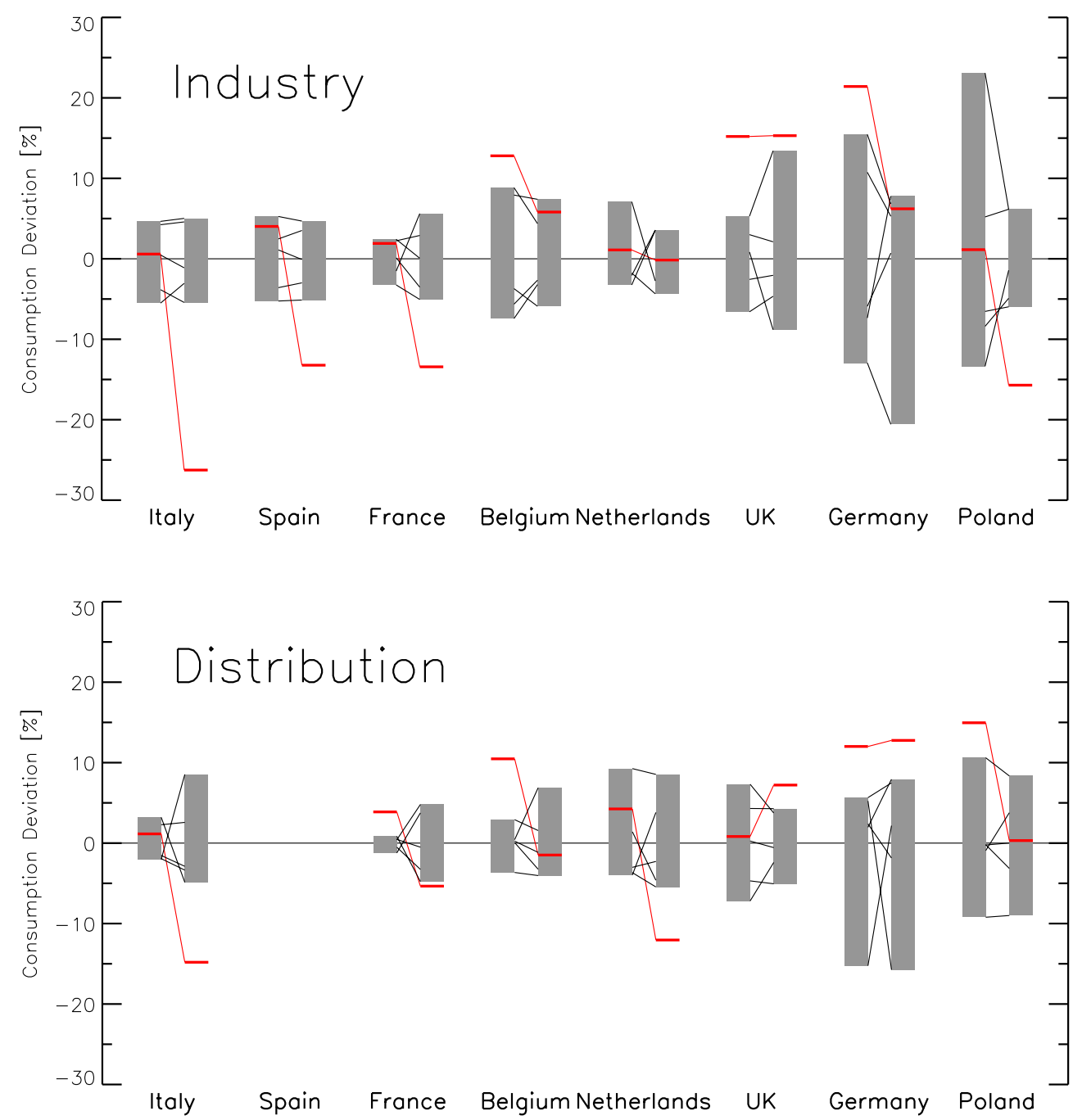

Figure 5. Deviations of the gas consumption in the industry (top) and the built environment, called distribution (bottom) in 2020 compared to the 2016-2019 mean. Two periods are considered: mid-January to end of February (left) and the first confinement period, which is country-specific (right); see vertical lines in Figure 4. The bars indicate the range of the deviation from the period 2016-2019 and provide some indications of the inter-annual variations. For each country, the bar on the left is for the pre-confinement period, while the bar on the right is for the confinement period. The thin black lines indicate the variations for each individual year of the 2016-2019 period. The red lines show the 2020 values. All gas consumptions have been corrected for temperature anomalies.

for cooking and hot water production. Gas distribution to the built environment therefore shows a strong seasonal cycle with a peak consumption in winter, and fluctuations that relate to temperature anomalies. Gas consumption in the electricity production sector shows very large variations linked to the total electricity demand, the weather-driven supply of solar and wind renewable electricity, the availability of nuclear, the relative distribution between coal, oil and gas that depends on market prices and climate policies. It is difficult to identify the impact of lockdown measures on gas consumption time series for the electricity production sector, given the combined effects from other sources of electricity. The electricity production sector is therefore excluded from our analysis. Additionally, we obtained daily gas consumption data for the City of Paris [administrative jurisdiction, 2.18 million people (Economic \& Affairs, 2018)] based on local pipeline flows. Since there is almost no industry in the jurisdiction of Paris, the use of natural gas can be assumed to come primarily from the built environment, although it may also include small power-plants used for district heating. District heat in Paris uses waste and biomass, and only $40 \%$ of fossil fuels. 
Second, we collected daily index values summarizing government responses to the COVID-19, given by the Oxford Covid-19 Government Response Tracker (OxCGRT) (Hale et al., 2020). The OxCGRT contains 19 indicators, grouped into "containment and closure policies", "economic policies", "health system policies" and "miscellaneous policies". Specific to the consumption in the built environment, we selected the "stay-at-home requirements". National containment and closure measures were adopted in Italy on 9 March with closure of all schools, most services and a large fraction of industrial activities. Similar measures followed in Spain on 15 March, in France on 17 March and in the UK on 23 March. In other countries like the Netherland, Germany or Poland studied here, the confinement measures were not as severe. These measures have had a large impact on people's daily life and caused an economic downturn. A GDP reduction of more than $15 \%$ has been reported for Italy, Spain and France (International Monetary Fund, 2020).

Third, we collected the Google Community Mobility Reports representing how frequency of visits and duration of stays change against a baseline period (median value from the 5-week period 3 January-6 February 2020), at different places. For the gas consumption in the built environment, we selected the data for "residential".

Last, we collected national data on building types from a cross analysis of the databases of (Economidou et al., 2011) and the Eurostat (European Commission, 2021). We extracted data on country population, final end uses of energy sources (electricity, gas, oil, coal, biomass) for commercial buildings, non-residential buildings, separated into energy used for space heating only and other end uses, average dwelling area, and total number of dwellings. These data are used to understand the country-specific characteristics of gas consumption changes with temperatures during the heating season.

\section{Data Availability Statement}

The raw data on daily natural gas flows for distribution and final consumption from all the operators in eight countries are available at the ENTSO-G transparency platform (https://transparency.entsog.eu/). Raw daily gas consumption data for Germany are available at GASPOOL (https://www.gaspool.de/en/) and NetConnect Germany (https://www.net-connect-germany.de/en-gb/), which have been merged in to Trading Hub Europe since October 2021 at https://www.tradinghub.eu/en-gb/. The data aggregated at country level are available at https:// doi.org/10.6084/m9.figshare.14762238.v1. The Oxford Covid-19 Government Response Tracker data are available through Hale et al. (2020). The Google Community Mobility Reports data are available at https://www. google.com/covid19/mobility/. National data on building types are available through Economidou et al. (2011) and at https://ec.europa.eu/energy/eu-buildings-database_en.

\section{Acknowledgments}

Y. Wang acknowledges the National Natural Science Foundation of China grant No. 42001104. K. Tanaka benefited from State assistance managed by the National Research Agency in France under the Programme d'Investissements d'Avenir under the reference ANR-19MPGA-0008. J. Penuelas acknowledges the Catalan government grant AGAUR-2020PANDE00117

\section{References}

Bertram, C., Luderer, G., Creutzig, F., Bauer, N., Ueckerdt, F., Malik, A., \& Edenhofer, O. (2021). COVID-19-induced low power demand and market forces starkly reduce CO2 emissions. Nature Climate Change, 11(3), 193-196. https://doi.org/10.1038/s41558-021-00987-x

Crippa, M., Solazzo, E., Huang, G., Guizzardi, D., Koffi, E., Muntean, M., et al. (2020). High resolution temporal profiles in the emissions database for global atmospheric research. Scientific Data, 7(1), 1-17. https://doi.org/10.1038/s41597-020-0462-2

Economic \& Affairs. (2018). 2018 Revision of World Urbanization Prospects. United Nations. https://www.un.org/development/desa/publications/2018-revision-of-world-urbanization-prospects.html

Economidou, M., Atanasiu, B., Despret, C., Maio, J., Nolte, I., Rapf, O., et al (2011). Europe's buildings under the microscope. A country-by-country review of the energy performance of buildings. Retrieved from https://www.osti.gov/etdeweb/biblio/21514343

Entso-G Transparency Platform. (2020). Retrieved from https://transparency.entsog.eu/

European Commission. (2021). EU buildings database [text]. Retrieved from https://ec.europa.eu/energy/eu-buildings-database en

Eurostat. (2020). Industrial production up by $12.4 \%$ in euro area and $11.4 \%$ in EU. Retrieved from https://ec.europa.eu/eurostat/web/ products-euro-indicators/-/4-14072020-ap

Eurostat. (2021). Retrieved from https://ec.europa.eu/eurostat/web/energy/data

Hale, T., Webster, S., Petherick, A., Phillips, T., \& Kira, B. (2020). Oxford COVID-19 government response tracker. Blavatnik School of Government. Retrieved from https://github.com/OxCGRT/covid-policy-tracker

Hersbach, H., Bell, B., Berrisford, P., Biavati, G., Horányi, A., Muñoz Sabater, J., et al. (2018). ERA5 hourly data on single levels from 1979 to present. Copernicus Climate Change Service (C3S) Climate Data Store (CDS). https://doi.org/10.24381/cds.adbb2d47

Hong, C., Ciais, P., Liu, Z., Boucher, O., Zhao, W., Gentine, P., et al (2021). Near-real-time and state-level monitoring of U.S. CO 2 emissions. Retrieved from https://eartharxiv.org/repository/view/2233/

IEA. (2020a). Gas 2020. Retrieved from https://www.iea.org/reports/gas-2020

IEA. (2020b). World energy outlook 2020. Retrieved from https://www.iea.org/reports/world-energy-outlook-2020

IEA. (2021). Natural gas information 2021 edition. Retrieved from https://www.iea.org/data-and-statistics/data-product/ natural-gas-information\#world-natural-gas-statistics

International Monetary Fund. (2020). World economic outlook. International Monetary Fund. https://www.imf.org/en/Publications/WEO/ Issues/2020/09/30/world-economic-outlook-october-2020 
Janssens-Maenhout, G., Crippa, M., Guizzardi, D., Muntean, M., Schaaf, E., Dentener, F., et al. (2017). EDGAR v4.3.2 global atlas of the three major greenhouse gas emissions for the period 1970-2012. Earth system science data discussions, 1-55. https://doi.org/10.5194/essd-2017-79

Le Quéré, C., Jackson, R. B., Jones, M. W., Smith, A. J. P., Abernethy, S., Andrew, R. M., et al. (2020). Temporary reduction in daily global CO 2 emissions during the COVID-19 forced confinement. Nature Climate Change, 10, 1-653. https://doi.org/10.1038/s41558-020-0797-x

Liu, Z., Ciais, P., Deng, Z., Lei, R., Davis, S. J., Feng, S., et al. (2020). Near-real-time monitoring of global CO2 emissions reveals the effects of the COVID-19 pandemic. Nature Communications, 11(1), 5172. https://doi.org/10.1038/s41467-020-18922-7

Liu, Z., Zhu, B., Ciais, P., Davis, S. J., Lu, C., Zhong, H., et al (2021). De-carbonization of global energy use during the COVID-19 pandemic. ArXiv:2102.03240 [Physics, q-Fin, Stat]. Retrieved from http://arxiv.org/abs/2102.03240

Pullano, G., Valdano, E., Scarpa, N., Rubrichi, S., \& Colizza, V. (2020). Evaluating the effect of demographic factors, socioeconomic factors, and risk aversion on mobility during the COVID-19 epidemic in France under lockdown: A population-based study. The Lancet Digital Health, 2(12), e638-e649. https://doi.org/10.1016/S2589-7500(20)30243-0 